\title{
Do ethnicity, degree of family relationship, and the spondyloarthritis subtype in affected relatives influence the association between a positive family history for spondyloarthritis and HLA-B27 carriership? Results from the worldwide ASAS cohort
}

Miranda van Lunteren ${ }^{1 *}$, Alexandre Sepriano ${ }^{1,2}$, Robert Landewé ${ }^{3,4}$, Joachim Sieper ${ }^{5,6}$, Martin Rudwaleit5,7, Désirée van der Heijde ${ }^{1}$ and Floris van Gaalen ${ }^{1}$

\begin{abstract}
Background: The Assessment of SpondyloArthritis international Society (ASAS) defines a positive family history (PFH) of spondyloarthritis (SpA) as the presence of ankylosing spondylitis (AS), acute anterior uveitis (AAU), reactive arthritis (ReA), inflammatory bowel disease (IBD), and/or psoriasis in first-degree relatives (FDR) or second-degree relatives (SDR). In two European cohorts, a PFH of AS and AAU, but not other subtypes, was associated with human leukocyte antigen B27 (HLA-B27) carriership in patients suspected of axial SpA (axSpA). Because the importance of ethnicity or degree of family relationship is unknown, we investigated the influence of ethnicity, FDR, or SDR on the association between a PFH and HLA-B27 carriership in patients suspected of axSpA.

Methods: Baseline data from the ASAS cohort of patients suspected of axSpA were analyzed. Univariable analyses were performed. Each disease (AS, AAU, psoriasis, IBD, ReA) in a PFH according to the ASAS definition was a determinant in separate models with HLA-B27 carriership as outcome. Analyses were stratified for self-reported ethnicity, FDR, and SDR. Analyses were repeated in multivariable models to investigate independent associations.
\end{abstract}

Results: A total of 594 patients were analyzed (mean [SD] age 33.7 [11.7] years; 46\% male; 52\% HLA-B27+; 59\% white, $36 \%$ Asian, 5\% other). A PFH was associated with HLA-B27 carriership in patients with a white $(\mathrm{OR}, 2.3,95 \% \mathrm{Cl}, 1.4-3.9)$ or Asian ethnicity $(\mathrm{OR}, 3.1,95 \% \mathrm{Cl}, 1.6-5.8)$ and with a PFH in FDR $(\mathrm{OR}, 2.9,95 \% \mathrm{Cl}, 1.8-4.5)$, but not with a PFH in SDR $(\mathrm{OR}, 1.7,95 \% \mathrm{Cl}, 0.7-3.8)$ or in other ethnicities. A PFH of AS was positively associated with HLA-B27 carriership in all subgroups (white OR, 7.1; 95\% Cl, 2.9-17.1; Asian OR, 5.7; 95\% Cl, 2.5-13.2; FDR OR, 7.8; 95\% Cl, 3.8-16.0; SDR OR, 3.7; $95 \% \mathrm{Cl}, 1.2-11.6)$. A PFH of AAU, ReA, IBD, or psoriasis was never positively associated with HLA-B27 carriership. In the multivariate analysis, similar results were found.

Conclusions: In the ASAS cohort, a PFH of AS, but not of AAU, ReA, IBD, or psoriasis, was associated with HLA-B27 carriership regardless of white or Asian ethnicity or degree of family relationship. This cohort and two European cohorts show that a PFH of AS and possibly a PFH of AAU can be used to identify patients who are more likely to be HLA-B27positive and therefore may have an increased risk of axSpA.

Keywords: Axial spondyloarthritis, HLA-B27, Positive family history, Ethnicity, Degree of family relationship

\footnotetext{
* Correspondence: m.van_lunteren@lumc.nl

'Department of Rheumatology, Leiden University Medical Center, P.O. Box

9600, 2300 RC Leiden, the Netherlands

Full list of author information is available at the end of the article
}

(c) The Author(s). 2018 Open Access This article is distributed under the terms of the Creative Commons Attribution 4.0 International License (http://creativecommons.org/licenses/by/4.0/), which permits unrestricted use, distribution, and

reproduction in any medium, provided you give appropriate credit to the original author(s) and the source, provide a link to the Creative Commons license, and indicate if changes were made. The Creative Commons Public Domain Dedication waiver (http://creativecommons.org/publicdomain/zero/1.0/) applies to the data made available in this article, unless otherwise stated. 


\section{Background}

Axial spondyloarthritis (axSpA) is a chronic inflammatory disease that causes inflammation mainly in the sacroiliac joints (SI) and spine [1]. In patients with ankylosing spondylitis (AS), also termed radiographic axSpA, susceptibility is thought to be largely genetically determined, and the strongest known genetic risk factor for axSpA is human leukocyte antigen B27 (HLA-B27) [1, 2]. Different prevalence rates of axSpA are reported across geographical regions, which have been related to the varying prevalence of HLA-B27 worldwide [3]. A family history of spondyloarthritis (SpA) is common in patients with AS [4], and HLA-B27-positive first-degree relatives of HLA-B27-positive patients with AS are 16 times more likely to develop AS than HLA-B27-positive individuals in the general population [5]. Additionally, several studies have shown that first-degree relatives of a patient with AS have a higher risk of developing AS than second-degree relatives [6-8]. Therefore, a positive family history (PFH) of SpA, and in particular a PFH in first-degree relatives of patients with $\mathrm{SpA}$, is thought to be a risk factor of axSpA in patients with chronic back pain (CBP), and a PFH of SpA is a component of several SpA classification criteria $[9,10]$.

The Assessment of SpondyloArthritis international Society (ASAS) defined, by consensus, a PFH of AS, acute anterior uveitis (AAU), reactive arthritis (ReA), inflammatory bowel disease (IBD), and/or psoriasis in first- or second-degree relatives as an SpA feature in the ASAS classification criteria for axSpA [11]. Because a PFH of SpA is thought to increase the risk for axSpA in patients with CBP, it has been incorporated into several referral strategies for patients with CBP suspected of axSpA $[12,13]$.

So far, only one study has investigated the performance of the definition of a PFH in identifying patients with an increased risk for axSpA. Ez-Zaitouni et al. reported that in two cohorts predominantly Caucasian CBP patients suspected of axSpA, a PFH for AS and AAU was positively associated with HLA-B27 carriership. A PFH for ReA, IBD, or psoriasis was not associated with HLA-B27 carriership and did not point to HLA-B27 carriership in patients with back pain [14]. Unfortunately, this study did not to distinguish between first- or second-degree relatives, and therefore it was unclear if a distinction in a PFH in first- or second-degree relatives matters. Moreover, because the study was performed in two European cohorts, it was unclear if the authors' findings are relevant to populations outside Europe.

The ASAS cohort provides a unique opportunity to study the performance of the current ASAS definition of a $\mathrm{PFH}$ in patients of different ethnicities who have CBP and are suspected of axSpA $[11,15,16]$. Therefore, we investigated in this international cohort the impact of ethnicity and degree of family relationship on the association between the current ASAS definition of a PFH and the presence of HLA-B27 in patients suspected of axSpA.

\section{Methods}

The ASAS cohort is an international cohort that includes patients with a suspicion of axSpA ( $>3$ months of back pain, age at onset $<45$ years, with or without peripheral symptoms) or peripheral SpA ( $\mathrm{pSpA}$; current peripheral arthritis and/or dactylitis and/or enthesitis but without current CBP) $[11,15,16]$. Worldwide, 975 patients were included by 29 ASAS centers between November 2005 and January 2009. Patients were included in a consecutive manner, including all eligible patients or every first to third eligible patient per day. Local ethical committees approved the study, and informed consent was obtained from all study participants before inclusion $[11,15,16]$.

\section{Data collection}

At baseline, clinical, laboratory, and imaging data were collected from all patients, including HLA-B27 carriership and radiography of the SI. Magnetic resonance imaging of the SI (MRI-SI) was considered obligatory for the first 20 patients of each center. Patients were diagnosed by the treating rheumatologist, and for each patient, the level of confidence regarding the diagnosis on an 11-point numerical rating scale from 0 (not confident at all) to 10 (very confident) was provided. For the current analysis, only patients with a certain diagnosis of axSpA or no axSpA (confidence level $\geq 6$ ) were analyzed.

In addition, patients were asked to report their ethnicity using an open-ended question. Self-reported ethnicities were white, Asian, black, East Indian, Hispanic/Latino, mixed, and Turkish. The self-reported ethnicities were reclassified into white, Asian, and other ethnicities (Hispanic/Latino $n=11$, black $n=7$, mixed $n=4$, Turkish $n=3$, East Indian $n=2$, unknown $=5$ ).

The ASAS expert definition was used to assess if patients had a PFH of SpA (ASAS PFH) (i.e., the presence of AS, AAU, psoriasis, IBD, and/or ReA in first- or second-degree relatives) [11]. Patients were asked to report if any family history disease was present in a relative and in which relative(s). In the ASAS expert definition, father, mother, sister, brother, daughter, and son are defined as first-degree relatives and grandmother, grandfather, aunt, uncle, niece, and nephew as second-degree relatives [11]. Furthermore, in addition to the ASAS definition, granddaughter, grandson, half-sister, and half-brother were also considered to be second-degree relatives.

\section{Data analysis}

Baseline data were analyzed. Continuous variables were presented as mean and SD and categorical variables as frequencies (proportions). Univariable logistic models, stratified by self-reported ethnicity or degree of family 
Table 1 Baseline characteristics of chronic back pain patients suspected of axial spondyloarthritis included in the ASAS cohort

\begin{tabular}{|c|c|}
\hline Characteristics & Data $(N=594)$ \\
\hline Age at baseline, years & $33.7(11.7)$ \\
\hline Male sex & $276(46 \%)$ \\
\hline Duration of back pain, years ${ }^{a}$ & $7.1(9.0)$ \\
\hline \multicolumn{2}{|l|}{ Self-reported ethnicity } \\
\hline White & $348(59 \%)$ \\
\hline Asian & $214(36 \%)$ \\
\hline Other ${ }^{b}$ & $32(5 \%)$ \\
\hline IBP (according to experts' definition) & $301 / 532(57 \%)$ \\
\hline Good response to NSAIDs ${ }^{c}$ & $274(46 \%)$ \\
\hline Peripheral arthritis ${ }^{d}$ & $197(33 \%)$ \\
\hline Enthesitis $^{d}$ & $241(41 \%)$ \\
\hline$A A U^{d}$ & $53(9 \%)$ \\
\hline Dactylitis $^{d}$ & $23(4 \%)$ \\
\hline Psoriasis $^{d}$ & $22(4 \%)$ \\
\hline $\mathrm{IBD}^{\mathrm{d}}$ & $8(1 \%)$ \\
\hline Positive family history according to ASAS definition & $135(23 \%)$ \\
\hline Positive family history of AS & $87(15 \%)$ \\
\hline Positive family history of AAU & $7(1 \%)$ \\
\hline Positive family history of ReA & $8(1 \%)$ \\
\hline Positive family history of IBD & $12(2 \%)$ \\
\hline Positive family history of Psoriasis & $36(6 \%)$ \\
\hline
\end{tabular}

Total number of SpA-related diseases in first- or second-degree relatives

Number of patients with one disease 120 (20\%)

Number of patients with two diseases $\quad 15(3 \%)$

Total number of family members with SpA-related diseases

$\begin{array}{ll}\text { Number of patients with one relative } & 102(17 \%) \\ \text { Number of patients with two relatives } & 30(5 \%) \\ \text { Number of patients with three relatives } & 3(1 \%)\end{array}$

Total number of patients with positive family history in

$\begin{array}{ll}\text { First-degree relatives only } & 100(17 \%) \\ \text { Second-degree relatives only } & 25(4 \%) \\ \text { Both first- and second-degree relatives } & 10(2 \%) \\ \text { HLA-B27 positivity } & 310(52 \%) \\ \text { Elevated CRP/ESR } & 185(31 \%) \\ \text { Definite radiographic sacroiliitis } & \\ \text { Presence of active inflammation on MRI-SI } & 119 / 593(20 \%) \\ & 189 / 424(45 \%)\end{array}$

Table 1 Baseline characteristics of chronic back pain patients suspected of axial spondyloarthritis included in the ASAS cohort (Continued)

\begin{tabular}{ll}
\hline Characteristics & Data $(N=594)$ \\
\hline Number of SpA features, & $2.4(1.6)$ \\
Clinical diagnosis of axSpA & $368(62 \%)$ \\
\hline
\end{tabular}

Abbreviations: AAU Acute anterior uveitis, AS Ankylosing spondylitis, ASAS Assessment of SpondyloArthritis international Society, (ax)SpA (Axial) spondyloarthritis, CRP C-reactive protein, ESR Erythrocyte sedimentation rate, HLA-B27 Human leukocyte antigen B27, IBD Inflammatory bowel disease, IBP Inflammatory back pain, MRI-SI Magnetic resonance imaging of the sacroiliac joints, NSAID Nonsteroidal anti-inflammatory drug, ReA Reactive arthritis, SI Sacroiliac joint

Results are presented as mean \pm SD unless specified otherwise

a $<5 \%$ missing values

b Self-reported ethnicity was missing for five patients, who are included in this category, and other self-reported ethnicities are black, East Indian, Hispanic/ Latino, mixed, or Turkish

c Back pain not present anymore or is much better $24-48$ hours after a full dose of NSAID

d Past or present condition

e Grade $\geq 2$ bilateral or grade $\geq 3$ unilateral

${ }^{f}$ Excluding HLA-B27 carriership and imaging

${ }^{\mathrm{g}}<20 \%$ missing values

${ }^{h}$ Level of confidence regarding the diagnosis is $\geq 6$

relationship (a PFH in first- or only second-degree relatives), were used to assess the association between each disease (AS, AAU, ReA, IBD, psoriasis) in a PFH and HLA-B27 carriership. The analyses were repeated in multivariable logistic models to investigate if each family history disease was associated, independently of other PFH subtypes, with HLA-B27 carriership. Patients with a PFH in both first- and second-degree relatives were classified into the group of patients with $\mathrm{PFH}$ in a first-degree relative $(n=11)$ for both the univariable and multivariable analyses. STATA SE version 14 software (StataCorp, College Station, TX, USA) was used to perform data analyses.

\section{Results}

In the ASAS cohort, 642 patients were diagnosed with a confidence level $\geq 6$ as axSpA or no axSpA. Patients were excluded from the analysis if the family history was missing $(n=48)$. For the current analysis, 594 patients were used. Patients had a mean age (SD) of 33.7 (11.7) years, and $46 \%$ were male. Mean symptom duration was 7.1 (9.0) years, and a mean of 2.4 (1.6) SpA features, excluding HLA-B27 and imaging, were present. Of the sample, $52 \%$ were HLA-B27-positive, $20 \%$ had radiographic sacroiliitis, and $45 \%$ had active inflammation by MRI-SI (Table 1). Sixty-two percent of the patients were diagnosed as axSpA.

In total, $59 \%$ of patients reported to be white, $36 \%$ to be Asian, and 5\% reported another ethnicity (Table 1 ). An ASAS PFH was reported by $23 \%$ of the patients; a $\mathrm{PFH}$ of AS was the most frequently reported family 
Table 2 Univariable associations between a positive family history and HLA-B27 carriership in patients suspected of axial spondyloarthritis $(n=594)$

\begin{tabular}{llll}
\hline HLA-B27+ & HLA-B27- & OR & $p$ Value \\
$(n=310)$ & $(n=284)$ & $(95 \% \mathrm{Cl})$ & \\
\hline
\end{tabular}

Positive family history according to ASAS definition

Stratified by self-reported ethnicity

\begin{tabular}{|c|c|c|c|c|}
\hline White & 54 & 26 & $\begin{array}{l}2.3 \\
(1.4-3.9)\end{array}$ & 0.001 \\
\hline Asian & 38 & 14 & $\begin{array}{l}3.1 \\
(1.6-5.8)\end{array}$ & 0.001 \\
\hline Other ethnicities ${ }^{a}$ & 2 & 1 & $\begin{array}{l}2.3 \\
(0.2-25.0)\end{array}$ & 0.509 \\
\hline
\end{tabular}

Stratified by degree of family relationship

$\begin{array}{lcclc}\begin{array}{l}\text { First-degree } \\ \text { relatives }\end{array} & \mathbf{7 9} & \mathbf{3 1} & \begin{array}{l}\mathbf{2 . 9} \\ \mathbf{( 1 . 8 - 4 . 5 )}\end{array} & <\mathbf{0 . 0 0 1} \\ \begin{array}{l}\text { Only second- } \\ \text { degree relatives }\end{array} & 15 & 10 & \begin{array}{l}1.7 \\ \text { (.7.7-3.8) }\end{array} & 0.212\end{array}$

Positive family history of AS

Stratified by self-reported ethnicity

$\begin{array}{lll}\text { White } & 37 & 6 \\ \text { Asian } & 35 & \mathbf{7} \\ \text { Other ethnicities }^{\mathrm{a}} & 2 & 0\end{array}$

Stratified by degree of family relationship

$\begin{array}{lcc}\begin{array}{l}\text { First-degree } \\ \text { relatives }\end{array} & \mathbf{6 1} & \mathbf{9} \\ \begin{array}{l}\text { Only second- } \\ \text { degree relatives }\end{array} & \mathbf{1 3} & \mathbf{4}\end{array}$

Positive family history of AAU

Stratified by self-reported ethnicity

$\begin{array}{lllll}\text { White } & 4 & 0 & \text { n.a. } & \text { n.a. } \\ \text { Asian } & 2 & 1 & 1.9 & 0.613 \\ & & & (0.2-20.7) & \\ \text { Other ethnicities }^{\mathrm{a}} & 0 & 0 & \text { n.a. } & \text { n.a. }\end{array}$

Stratified by degree of family relationship

$\begin{array}{lcc}\begin{array}{l}\text { First-degree } \\ \text { relatives }\end{array} & 5 & 1 \\ \begin{array}{l}\text { Only second- } \\ \text { degree relatives }\end{array} & 1 & 0\end{array}$

Positive family history of ReA

Stratified by self-reported ethnicity

$\begin{array}{lllll}\text { White } & 2 & 2 & 0.9 & 0.924 \\ & & & (0.1-6.5) & \\ \text { Asian } & 1 & 3 & 0.3 & 0.302 \\ & & & (0.03-2.9) & \\ \text { Other ethnicities }^{\mathrm{a}} & 0 & 0 & \text { n.a. } & \text { n.a. }\end{array}$

Stratified by degree of family relationship

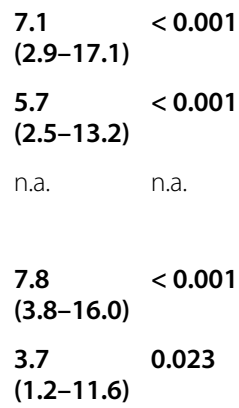

$4.7 \quad 0.162$

$(0.5-40.1)$

n.a. $\quad$ n.a.

n.a. n.a.

0.735

n.a
Table 2 Univariable associations between a positive family history and HLA-B27 carriership in patients suspected of axial spondyloarthritis $(n=594)$ (Continued)

\begin{tabular}{|c|c|c|c|c|}
\hline & $\begin{array}{l}\text { HLA-B27+ } \\
(n=310)\end{array}$ & $\begin{array}{l}\text { HLA-B27- } \\
(n=284)\end{array}$ & $\begin{array}{l}\mathrm{OR} \\
(95 \% \mathrm{Cl})\end{array}$ & $p$ Value \\
\hline \multicolumn{5}{|l|}{ Positive family history of IBD } \\
\hline \multicolumn{5}{|c|}{ Stratified by self-reported ethnicity } \\
\hline White & 2 & 7 & $\begin{array}{l}0.3 \\
(0.05-1.2)\end{array}$ & 0.089 \\
\hline Asian & 0 & 2 & n.a. & n.a. \\
\hline Other ethnicities ${ }^{a}$ & 0 & 1 & n.a. & n.a. \\
\hline \multicolumn{5}{|c|}{ Stratified by degree of family relationship } \\
\hline First-degree relatives & 1 & 7 & $\begin{array}{l}0.1 \\
(0.02-1.0)\end{array}$ & 0.054 \\
\hline $\begin{array}{l}\text { Only second-degree } \\
\text { relatives }\end{array}$ & 1 & 3 & $\begin{array}{l}0.3 \\
(0.03-2.9)\end{array}$ & 0.294 \\
\hline \multicolumn{5}{|c|}{ Positive family history of psoriasis } \\
\hline \multicolumn{5}{|c|}{ Stratified by self-reported ethnicity } \\
\hline White & 16 & 15 & $\begin{array}{l}1.0 \\
(0.5-2.0)\end{array}$ & 0.938 \\
\hline Asian & 2 & 2 & $\begin{array}{l}0.9 \\
(0.1-6.5)\end{array}$ & 0.926 \\
\hline Other ethnicities ${ }^{a}$ & 0 & 1 & n.a. & n.a. \\
\hline \multicolumn{5}{|c|}{ Stratified by degree of family relationship } \\
\hline First-degree relatives & 15 & 14 & $\begin{array}{l}1.0 \\
(0.5-2.1)\end{array}$ & 0.949 \\
\hline $\begin{array}{l}\text { Only second-degree } \\
\text { relatives }\end{array}$ & 3 & 4 & $\begin{array}{l}0.7 \\
(0.2-3.1)\end{array}$ & 0.620 \\
\hline
\end{tabular}

Statistically significant results are printed in bold Abbreviations: $A A U$ Acute anterior uveitis, AS Ankylosing spondylitis, HLA-B27 Human leukocyte antigen B27, IBD Inflammatory bowel disease, n.a. Not applicable, ReA Reactive arthritis

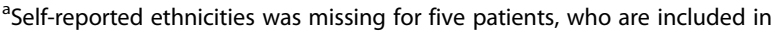
this category, and other ethnicities are black, East Indian, Hispanic/Latino, mixed, or Turkish

history, with $15 \%$ (64\% of all PFH), and a PFH of AAU was the least often reported, with $1 \%$ (5\% of all PFH), among all patients (Table 1). An ASAS PFH in first-degree relatives only was reported in $17 \%$ of patients, in second-degree relatives in $4 \%$, and in both firstand second-degree relatives in $2 \%$ of the patients.

An ASAS PFH and a PFH of AS were positively associated with HLA-B27 in all patients suspected of axSpA (ASAS PFH OR, 2.6; 95\% CI, 1.7-3.9; PFH of AS OR, 6.5; 95\% CI, 3.5-12.1). When these patients were stratified according to ethnicity and degree of family relationship, positive associations were found between an ASAS PFH and HLA-B27 carriership in patients with a self-reported white (OR, 2.3; 95\% CI, 1.4-3.9) or Asian ethnicity (OR, 3.1; 95\% CI, 1.6-5.8) and with a PFH in first-degree relatives (OR, 2.9; 95\% CI, 1.8-4.5), but not in second-degree relatives (OR, 1.7; 95\% CI, 0.7-3.8) (Table 2). A PFH of AS was positively associated with 
HLA-B27 carriership in all subgroups (white OR, 7.1; 95\% CI, 2.9-17.1; Asian OR, 5.7; 95\% CI, 2.5-13.2; first-degree relatives OR, 7.8; 95\% CI, 3.8-16.0; second-degree relatives OR, 3.7; 95\% CI, 1.2-11.6). A PFH of AAU, ReA, IBD, or psoriasis was not positively associated with HLA-B27 carriership in patients suspected of axSpA, regardless of the degree of family relationship or ethnicity (Table 2). In the multivariable analysis, similar results were found (data not shown).

\section{Discussion}

In patients suspected of axSpA in the worldwide ASAS cohort, a PFH of AS was the predominant PFH subtype and was associated, independently of other PFH subtypes, with HLA-B27 carriership, regardless of self-reported ethnicity or degree of family relationship. No positive associations were found between a PFH of AAU, ReA, IBD, or psoriasis and HLA-B27 carriership. However, it should be noted that in patients with CBP suspected of axSpA, a $\mathrm{PFH}$ of AAU, ReA, and IBD was less common than a PFH of AS, which is in line with previous studies. Somewhat stronger associations were found for patients with white ethnicity and for patients with a PFH in first-degree relatives. Nonetheless, a PFH of AS was strongly associated with HLA-B27 carriership in both white and Asian patients and in both first- and second-degree relatives.

Our study is in line with the study of Ez-Zaitouni et al. in two European cohorts because they reported that a PFH of AS is associated with HLA-B27 carriership, but a $\mathrm{PFH}$ of $\mathrm{ReA}$, IBD, or psoriasis was not [14]. In this study, a PFH of ReA, IBD, and AAU was also less common than a PHF of AS. However, in contrast to our findings, Ez-Zaitouni et al. [14] also found that a PFH of AAU contributed to the identification of axSpA because this was associated with HLA-B27 carriership in patients with CBP. In our study, a $\mathrm{PFH}$ of AAU was rarely reported (1\%), as compared with $5-6 \%$ in the study of Ez-Zaitouni et al., which may limit detecting a possible association with HLA-B27 carriership owing to sample size. We have no proper explanation why a PFH of AAU was less common in our study. It may be attributed to differences in ethnicity (European cohorts vs. worldwide cohort in our study). However, the frequency of a PFH of AAU was similarly low in white and Asian patients in our cohort $(0.7 \%$ vs. $0.5 \%)$. Moreover, the frequency of AAU in patients suspected of axSpA was similar in our cohort (9\% overall; $10 \%$ in white and $6 \%$ in Asian patients) as compared with $8 \%$ in the study by Ez-Zaitouni et al.

In a general practice setting or other low SpA prevalence settings, a PFH of AS could be used for identifying HLA-B27-positive patients among patients suspected of axSpA. The RADAR study showed that HLA-B27 is a good referral tool for identifying patients with axSpA, because HLA-B27 has a higher sensitivity than an ASAS
PFH [17]. Therefore, it is recommended that a PFH of AS should be used as a criterion for referral to secondary care only when HLA-B27 testing is not feasible.

The current study investigated patients with axial symptoms (i.e., patients with CBP suspected of axSpA) of the ASAS cohort, and therefore it is important to emphasize that the results are not applicable to patients with predominantly peripheral symptoms. In patients with predominantly peripheral symptoms, a PFH of, for example, psoriasis could be important and relevant for identifying patients with an increased risk of pSpA [15].

An important strength of this study is that the ASAS study is a worldwide cohort, which enabled us to investigate different self-reported ethnicities. Another strength is the availability of extensive information on family history, which allowed us to investigate the role of first- and second-degree relatives for each manifestation of a PFH. A major limitation is the self-reported family history by patients. This could lead either to an underestimation if a patient forgets or is unaware that a relative has an SpA-related disease or to an overestimation if a patient is confused or mistaken in the type of disease of a relative. Nevertheless, in a clinical setting, the physician usually has to depend on patient-reported family history. Another limitation is the small percentage of patients with self-reported ethnicity other than being white or Asian. Only $5 \%$ of the patients reported to be Hispanic/Latino, black, mixed, Turkish, East Indian, or unknown ethnicity. Therefore, the results are applicable only to white or Asian populations, which corresponds to the largest population with axSpA worldwide [18]. Preferably, future research into the value of a PFH for identifying HLA-B27 carriership should be conducted in patients with other ethnicities. In this study, we focused on the use of a PFH of SpA for identifying patients with CBP who are at an increased risk of HLA-B27 carriership, but we did not investigate the potential added value of a PFH in diagnosing patients with axSpA. We are currently analyzing data from three independent axSpA cohorts to address this issue.

\section{Conclusions}

Our data, in combination with data from two European cohorts, show that a PFH of AS and possibly also a PFH of AAU, regardless of ethnicity (white or Asian) or degree of family relationship, is valuable for identifying patients with CBP who could be HLA-B27-positive and consequently have an increased risk of axSpA.

\section{Abbreviations}

AAU: Acute anterior uveitis; AS: Ankylosing spondylitis; ASAS: Assessment of SpondyloArthritis international Society; axSpA: Axial spondyloarthritis; CBP: Chronic back pain; CRP: C-reactive protein; ESR: Erythrocyte sedimentation rate; FDR: First-degree relative; HLA-B27: Human leukocyte antigen B27; IBD: Inflammatory bowel disease; IBP: Inflammatory back pain; MRI: Magnetic resonance imaging; NSAID: Nonsteroidal anti-inflammatory drug; PFH: Positive family history; pSpA: Peripheral spondyloarthritis; 
ReA: Reactive arthritis; SDR: Second-degree relative; SI: Sacroiliac joints; SpA: Spondyloarthritis

\section{Availability of data and materials}

The dataset used and/or analyzed during the current study are available from the corresponding author on reasonable request.

\section{Authors' contributions}

$M v L, D v d H$, and FvG were responsible for the study conception and design $R L, J S, M R$, and DvdH were responsible for acquisition of the data. MvL, DvdH, and FvG participated in interpretation and analysis of the data. MvL drafted and wrote the manuscript. MvL, AS, RL, JS, MR, DvdH, and FvG were involved in critically revising the manuscript for important intellectual content. All authors read and approved the final manuscript.

\section{Ethics approval and consent to participate}

The ASAS cohort has been approved by the medical ethics committee of each participating center, and all patients gave written informed consent.

\section{Consent for publication}

Not applicable.

\section{Competing interests}

The authors declare that they have no competing interests.

\section{Publisher's Note}

Springer Nature remains neutral with regard to jurisdictional claims in published maps and institutional affiliations.

\section{Author details}

'Department of Rheumatology, Leiden University Medical Center, P.O. Box 9600, 2300 RC Leiden, the Netherlands. ${ }^{2}$ NOVA Medical School, Universidade Nova de Lisboa, Lisbon, Portugal. ${ }^{3}$ Department of Rheumatology, Amsterdam Rheumatology \& Immunology Center, Amsterdam, the Netherlands. ${ }^{4}$ Department of Rheumatology, Zuyderland Hospital, Heerlen, the Netherlands. ${ }^{5}$ Department of Rheumatology, Charité Campus Benjamin Franklin, Berlin, Germany. ${ }^{6}$ German Rheumatism Research Centre, Berlin, Germany. ${ }^{7}$ Department of Internal Medicine and Rheumatology, Klinikum Bielefeld Rosenhöhe, Bielefeld, Germany.

Received: 5 April 2018 Accepted: 12 July 2018

Published online: 03 August 2018

\section{References}

1. Sieper J, Poddubnyy D. Axial spondyloarthritis. Lancet. 2017;390(10089):73-84.

2. Brown MA, Kennedy LG, MacGregor AJ, Darke C, Duncan E, Shatford JL, Taylor A, Calin A, Wordsworth P. Susceptibility to ankylosing spondylitis in twins: the role of genes, HLA, and the environment. Arthritis Rheum. 1997; 40(10):1823-8

3. Mathieu A, Paladini F, Vacca A, Cauli A, Fiorillo MT, Sorrentino R. The interplay between the geographic distribution of HLA-B27 alleles and their role in infectious and autoimmune diseases: a unifying hypothesis. Autoimmun Rev. 2009;8(5):420-5.

4. Bedendo A, Glorioso S, Venturi Pasini C, Fabiano F, Casara D, Cavallo A, Todesco S. A family study of ankylosing spondylitis. Rheumatol Int. 1984;5(1):29-32.

5. van der Linden SM, Valkenburg HA, de Jongh BM, Cats A. The risk of developing ankylosing spondylitis in HLA-B27 positive individuals: a comparison of relatives of spondylitis patients with the general population. Arthritis Rheum. 1984;27(3):241-9.

6. Brown MA, Laval SH, Brophy S, Calin A. Recurrence risk modelling of the genetic susceptibility to ankylosing spondylitis. Ann Rheum Dis. 2000;59(11):883-6.

7. Kim HW, Choe HR, Lee SB, Chang WI, Chae HJ, Moon JY, Kang J, Lee S, Song YW, Lee EY. Phenotype difference between familial and sporadic ankylosing spondylitis in Korean patients. J Korean Med Sci. 2014;29(6):782-7.

8. Geirsson AJ, Kristjansson K, Gudbjornsson B. A strong familiality of ankylosing spondylitis through several generations. Ann Rheum Dis. 2010;69(7):1346-8.

9. Amor B, Dougados M, Mijiyawa M. Criteria of the classification of spondylarthropathies [in French]. Rev Rhum Mal Osteoartic. 1990;57(2):85-9.
10. Dougados $M$, van der Linden $S$, Juhlin R, Huitfeldt B, Amor B, Calin A, Cats A, Dijkmans B, Olivieri I, Pasero G, et al. The European Spondylarthropathy study group preliminary criteria for the classification of spondylarthropathy. Arthritis Rheum. 1991;34(10):1218-27.

11. Rudwaleit M, van der Heijde D, Landewé R, Listing J, Akkoc N, Brandt J, Braun J, Chou CT, Collantes-Estevez E, Dougados M, et al. The development of Assessment of SpondyloArthritis international Society classification criteria for axial spondyloarthritis (part II): validation and final selection. Ann Rheum Dis. 2009;68(6):777-83.

12. Poddubnyy D, van Tubergen A, Landewé R, Sieper J, van der Heijde D, Assessment of SpondyloArthritis international Society (ASAS). Development of an ASAS-endorsed recommendation for the early referral of patients with a suspicion of axial spondyloarthritis. Ann Rheum Dis. 2015;74(8):1483-7.

13. Abawi $O$, van den Berg R, van der Heijde D, van Gaalen FA. Evaluation of multiple referral strategies for axial spondyloarthritis in the SPondyloArthritis Caught Early (SPACE) cohort. RMD Open. 2017;3(1):e000389.

14. Ez-Zaitouni Z, Hilkens A, Gossec L, Berg IJ, Landewé R, Ramonda R, Dougados M, van der Heijde D, van Gaalen F. Is the current ASAS expert definition of a positive family history useful in identifying axial spondyloarthritis? Results from the SPACE and DESIR cohorts. Arthritis Res Ther. 2017;19(1):118.

15. Rudwaleit M, van der Heijde D, Landewé R, Akkoc N, Brandt J, Chou CT, Dougados M, Huang F, Gu J, Kirazli Y, et al. The Assessment of SpondyloArthritis international Society classification criteria for peripheral spondyloarthritis and for spondyloarthritis in general. Ann Rheum Dis. 2011; 70(1):25-31

16. Sepriano A, Landewé R, van der Heijde D, Sieper J, Akkoc N, Brandt J, Braun J, Collantes-Estevez E, Dougados M, Fitzgerald O, et al. Predictive validity of the ASAS classification criteria for axial and peripheral spondyloarthritis after followup in the ASAS cohort: a final analysis. Ann Rheum Dis. 2016;75(6):1034-42.

17. Sieper J, Srinivasan S, Zamani O, Mielants H, Choquette D, Pavelka K, Loft AG, Géher P, Danda D, Reitblat T, et al. Comparison of two referral strategies for diagnosis of axial spondyloarthritis: the Recognising and Diagnosing Ankylosing spondylitis Reliably (RADAR) study. Ann Rheum Dis. 2013;72(10):1621-7.

18. Dean LE, Jones GT, MacDonald AG, Downham C, Sturrock RD, Macfarlane GJ. Global prevalence of ankylosing spondylitis. Rheumatology (Oxford). 2014; 53(4):650-7.

Ready to submit your research? Choose BMC and benefit from:

- fast, convenient online submission

- thorough peer review by experienced researchers in your field

- rapid publication on acceptance

- support for research data, including large and complex data types

- gold Open Access which fosters wider collaboration and increased citations

- maximum visibility for your research: over $100 \mathrm{M}$ website views per year

At $\mathrm{BMC}$, research is always in progress.

Learn more biomedcentral.com/submissions 